\title{
INNOVATIVE TECHNOLOGIES OF HUMAN CAPITAL DEVELOPMENT OF CHILDREN WITH DISABILITIES ${ }^{1}$
}

\author{
Nataliya A. Mikhaylova \\ Moscow State University of Humanities and Economics, Moscow, Russian Federation \\ Inna L. Litvinenko \\ Moscow State University of Humanities and Economics, Moscow, Russian Federation
}

\begin{abstract}
Building up human capital is the main element of the Russian regions' strategic development, since it is a necessary basis for economic growth. Achieving high economic performance without state influence on human capital at the present stage is not possible. The article is devoted to the problem of human capital development in the context of demographic crisis in Russia, the peculiarities of migration and the high level of disabled people among employable population. Theoretical and methodological foundations of human capital formation are analyzed in the context of the need to increase the innovativeness of the Russian economy. The authors identified innovative approaches to the formation of human capital of children with disabilities in the process of obtaining education and achieving acmeological growth. The basis of the policy of increasing human capital should be an updated and objectively formed strategy for the socio-economic development of the territory. The main element of the new strategy should be measures aimed at economic growth, increasing the productivity of economic entities in the region, increasing budget profitability, and increasing the financial security of socially disadvantaged categories of citizens. The development of education, healthcare and social services should be additional elements of the region's policy of increasing human capital.
\end{abstract}

Key words: human capital, innovative economy, health capital, children with disabilities, inclusive education, human potential.

Citation. Mikhaylova N.A., Litvinenko I.L. Innovative Technologies of Human Capital Development of Children with Disabilities. Vestnik Volgogradskogo gosudarstvennogo universiteta. Ekonomika [Journal of Volgograd State University. Economics], 2021, vol. 23, no. 3, pp. 74-83. (in Russian). DOI: https://doi.org/10.15688/ek.jvolsu.2021.3.7

УДК 331.5

ББК 65.240
Дата поступления статьи: 18.06.2021

Дата принятия статьи: 02.07.2021

\section{ИННОВАЦИОННЫЕ ТЕХНОЛОГИИ РАЗВИТИЯ ЧЕЛОВЕЧЕСКОГО КАПИТАЛА ДЕТЕЙ С ОГРАНИЧЕННЫМИ ВОЗМОЖНОСТЯМИ ЗДОРОВЬЯ ${ }^{1}$}

\section{Наталия Александровна Михайлова}

Московский государственный гуманитарно-экономический университет, г. Москва, Российская Федерация

\section{Инна Леонтьевна Литвиненко}

Московский государственный гуманитарно-экономический университет, г. Москва, Российская Федерация

Аннотация. Наращивание человеческого капитала является основным элементом стратегического развития регионов России, так как именно человеческий капитал является необходимой основой для экономического роста, а достижение высоких показателей экономики без государственного воздействия на человеческий капитал на современном этапе не представляется возможным. Статья посвящена проблеме развития 
человеческого капитала в условиях демографического кризиса в России, особенностей миграции и высокого уровня инвалидности трудоспособного населения. Теоретические и методологические основы формирования человеческого капитала анализируются в контексте необходимости повышения инновационности российской экономики. Авторы определили инновационные подходы к формированию человеческого капитала детей с ограниченными возможностями здоровья в процессе получения образования и достижения акмеологического роста. Основу политики наращивания человеческого капитала должна составить актуализированная и объективно сформированная стратегия социально-экономического развития территории. Основным элементом новой стратегии должны являться мероприятия, направленные на экономический рост, увеличение производительности хозяйствующих субъектов региона, повышение доходности бюджета, увеличение финансовой обеспеченности социально незащищенных категорий граждан. Дополнительными элементами политики наращивания человеческого капитала региона должно стать развитие образования, здравоохранения и социальной сферы.

Ключевые слова: человеческий капитал, инновационная экономика, капитал здоровья, дети с ограниченными возможностями здоровья, инклюзивное образование, человеческий потенциал.

Цитирование. Михайлова Н. А., Литвиненко И. Л. Инновационные технологии развития человеческого капитала детей с ограниченными возможностями здоровья // Вестник Волгоградского государственного университета. Экономика. - 2021. - Т. 23, № 3. - C. 74-83. - DOI: https://doi.org/10.15688/ek.jvolsu.2021.3.7

\section{Введение}

Проблемы развития человеческого капитала инвалидов с детства и детей-инвалидов в мировых экономиках являются актуальными, так как это категории детей, нуждающихся в особом уходе и развитии.

Кроме того, существует проблема, связанная с увеличением численности детей-инвалидов в возрасте до 18 лет. Если в 90-х годах прошлого века приблизительное количество детей-инвалидов в стране было 150 тыс. человек, то в настоящее время эта цифра увеличена до 540 тыс. человек. Такая динамика увеличения числа детей-инвалидов снижает уровень человеческого капитала в России. Ведь эти дети не смогут стать трудоспособным населением, накапливать опыт работы и развиваться как полноценные граждане страны [Байрамов и др., 2012].

На сегодняшний день человеческий капитал представляет собой не только образование и профессиональные навыки человека, но и качество его жизни, включающее, согласно исследованиям Всемирного банка, потребительские расходы, уровень развития системы здравоохранения, культуры, расходы государства на социальную сферу и т. д. В современном мире человеческий капитал становится первоочередным инструментом для достижения национального благополучия [Карпенко, 2015].

Многие преуспевающие на сегодняшний день государства добились высоких по- казателей развития экономики, используя в качестве основного ресурса человеческий капитал.

\section{Роль человеческого капитала} в развитии инновационной экономики

Формирование человеческого капитала не ограничивается образованием, а включает в себя все сферы жизни человека, способные оказать влияние на результаты его профессиональной деятельности, в связи с чем важное значение приобретают уровни развития социальной сферы, здравоохранения, культуры, досуга людей, уровень и структура доходов населения, качество предоставляемых услуг, доступность жилья, качество и продолжительность жизни и т. д. (см. рис. 1).

В сегодняшних условиях стало очевидным, что залогом экономического благосостояния, как национального, так и в разрезе регионов, является ориентация экономики на инновационный путь развития.

Инновационная экономика - это особый тип экономики, который характеризуется первоочередной ролью инноваций, технологического совершенствования, экспорта высокотехнологичной продукции и технологий в достижение высоких экономических результатов. Главное отличие инновационной экономики состоит в том, что высокий уровень доходов обеспечен не материальным увеличением объемов производства и финансовых вливаний в него, а интеллектом новаторов и ученых, что 


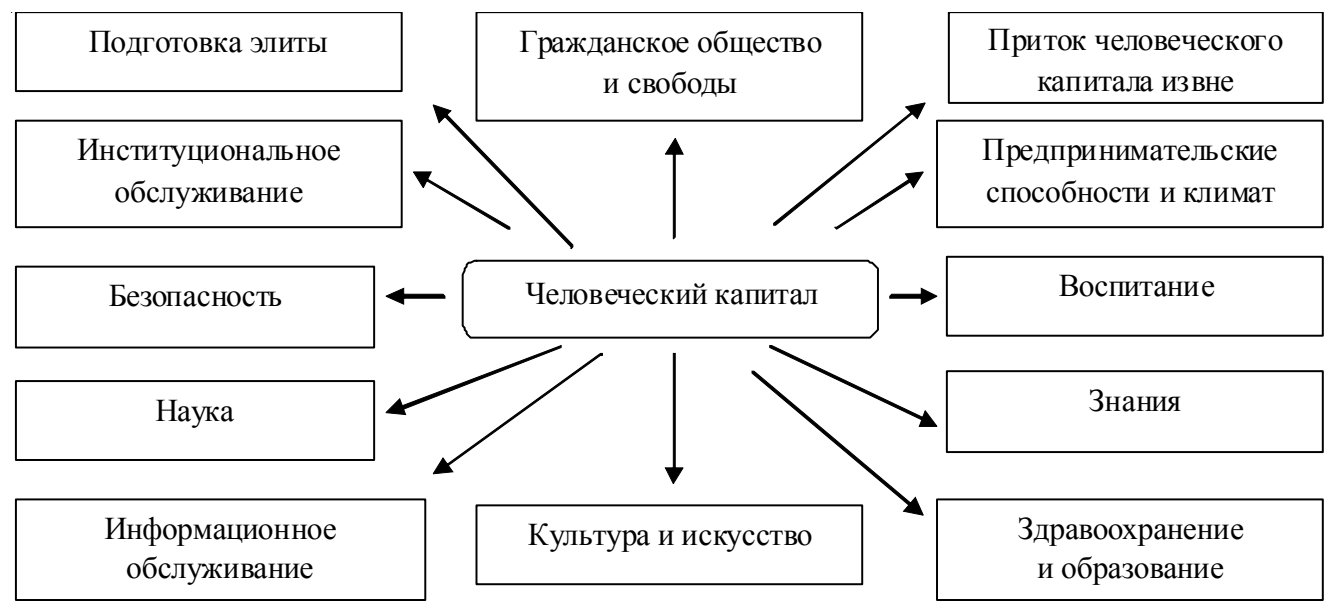

Рис. 1. Источники формирования человеческого капитала

Примечание. Составлено авторами.

определяет доминирующую роль человеческого фактора в создании эффективной инновационной экономики [Лаптев, 2016].

Говоря об инновационной экономике, следует понимать, что она может иметь место в отдельных регионах, но все же наибольшая эффективность достигается при национальной переориентации экономики в сторону инноваций и технологий, что дает устойчивую базу для дальнейшего регионального развития.

В рамках перехода к инновационной экономике есть два направления: развитие инновационной инфраструктуры и развитие человеческого капитала как определяющего фактора в создании и внедрении инноваций в экономику. Как показывает практика, переход к инновационной экономике возможен, как минимум, при совокупном расширении инновационной инфраструктуры и развитии человеческого капитала, а многие исследователи вовсе считают, что человеческий капитал и объем вложений в него являются определяющим фактором при переходе к инновационной экономике [Инновационно ориентированная региональная политика ..., 2017].

При этом в России большее внимание уделяется развитию инновационной инфраструктуры. Однако именно человеческий капитал как ресурс имеет решающее значение в данном вопросе.

Инновационная экономика представляет собой в первую очередь экономику знаний и информации, в которой скорость развития определяется величиной научно-технического прогресса. При этом очевидно, что научнотехнический прогресс и процесс внедрения его результатов в производство невозможны в отсутствие квалифицированных кадров, сформированного научного сообщества, высокого уровня развития техники и научной мысли. Кроме того, возрастает роль и личностных качеств людей: для инновационной экономики характерны требования к мобильности, гибкости, профессиональной переориентации, способности к постоянному обучению специалистов [Николаева и др., 2015].

Таким образом, человеческий капитал является основополагающим фактором для развития эффективной инновационной экономики.

Роль человеческого капитала в региональном развитии обусловлена высокой степенью его влияния на социально-экономическое развитие территории.

В рамках данного вопроса принято выделять региональный человеческий капитал, который, с одной стороны, характеризуется совокупностью человеческих ресурсов территории, а с другой - формами и отношениями по поводу использования и развития человеческих ресурсов. При этом человеческие ресурсы региона необходимо рассматривать с трех позиций: как кадровый потенциал территории, как потребителей производимых на территории региона товаров и услуг и как социальное окружение.

Уровень развития человеческого капитала региона имеет непосредственное влияние на экономическое благосостояние региона, 
инвестиционную привлекательность территории, социально-культурный облик, структуру миграции, производственную мощность, величину валового регионального продукта и т. д.

Учитывая высокую важность величины человеческого капитала в развитии территории, в современных условиях, как правило, конкурентные преимущества получают те регионы, которые вкладывают значительную часть финансовых ресурсов в социальную сферу, здравоохранение, образование и т. д.

Жители территорий, в которых активно ведется политика по сохранению и приумножению человеческого капитала, отличаются по ряду параметров:

- значительная часть населения обладает базовыми профессиональными знаниями и навыками, при этом присутствует глубокая специализация в различных сферах производства;

- люди склонны к получению новых знаний - повышению квалификации, а также к освоению дополнительных профессий, то есть профессиональной переориентации;

- население легко адаптируется к новым экономическим условиям, мобильно, психологически устойчиво к переменам, готово к рискам;

- в целом благосостояние региона имеет высокие показатели, что положительным образом сказывается на формировании малого и среднего бизнеса территории;

- здоровье рассматривается населением как объект инвестиций, что способствует повышению качества жизни, улучшению демографической ситуации;

- население региона в основной своей массе законопослушно и общественно активно [Bason, 2017].

Все вышеперечисленные характеристики носителей человеческого капитала позволяют территории достигать высоких показателей социально-экономического развития; кроме того, человеческий капитал, как источник благосостояния территории, характеризуется мультипликативным эффектом, то есть для сохранения существующих темпов развития в регионах, где человеческий капитал достаточно высок, государству требуется меньшее количество средств, чем в регионах с низким уровнем человеческого капитала [Лаптев, 2016].
Таким образом, человеческий капитал в современных условиях становится одним из ключевых элементов, необходимых для социально-экономического развития территорий, что обусловливает необходимость переориентации региональной политики к направлениям развития человеческого потенциала территории.

Так, следует отметить, что ряд экономически развитых на сегодняшний день государств достигли высокого уровня своего благосостояния благодаря эффективному использованию человеческого капитала как инструмента социально-экономического развития. Среди них, например, Швеция и Финляндия.

Теоретические исследования и практика применения человеческого капитала в целях социально-экономического развития территорий показали, что он является одним из мощнейших экономических инструментов. Уровень развития человеческого капитала региона имеет непосредственное влияние на экономическое благосостояние региона, инвестиционную привлекательность территории, социально-культурный облик, структуру миграции, производственную мощность, величину валового регионального продукта и т. д.

Люди, как носители регионального человеческого капитала, в регионах с высоким уровнем данного показателя обладают повышенным уровнем знаний и профессиональных навыков, склонны к постоянному обучению, мобильны, активны, ответственно относятся к своему здоровью, ведут общественную деятельность, что в совокупности само по себе определяет социально-экономическое благополучие территории.

Также отдельно необходимо обратить внимание на роль человеческого капитала в построении инновационной экономики, которая в современных условиях стала одним из основных направлений развития. Учитывая, что инновационная экономика представляет собой экономику знаний и информации, человек и человеческий капитал становятся в ней основополагающими ресурсами. Развитие инновационной экономики невозможно без научных разработок, специальных знаний, высококвалифицированного труда, людей, способных быстро и безболезненно адаптироваться к новым условиям [Litvinenko, 2020]. 
Таким образом, в условиях ограниченности производственных ресурсов и постоянного стремления к экономическому росту роль человеческого капитала постоянно увеличивается. Именно человеческий капитал становится основополагающим инструментом в развитии как отдельных регионов, так и государств в целом.

Учитывая важную роль уровня человеческого капитала в национальном благосостоянии, в современном государственном управлении все большее значение приобретает государственное воздействие на человеческий капитал, которое в ряде стран является отдельным институтом управления.

Государственное воздействие на человеческий капитал представляет собой комплекс мер государства, направленных на сохранение, развитие и воспроизводство человеческого капитала, который в последующем используется в производственной сфере. Среди основных направлений государственного воздействия на человеческий капитал можно выделить меры поддержки, направленные на социально незащищенные категории граждан, вложения в здравоохранение, образование, науку и культуру, а также действия, направленные на повышение качества жизни граждан, имеющих право на получение адресной социальной помощи за счет бюджетных средств и внебюджетных фондов.

Так, актуальной становится разработка системы адресных выплат для семей с детьми, что должно мотивировать трудоспособных на реализацию в полном объеме их человеческого капитала на рынке труда, а также развитие рынка поддерживающих здоровье технологий и устройств для инвалидов и лиц с ограниченными возможностями здоровья [Профессиональная ориентация ..., 2017]. Для решения этой задачи потребуются разработка и принятие технологических дорожных карт развития инновационных технологий по следующим направлениям:

- робототехника;

- биомехатроника;

- биомеханика;

- нейропротезирование;

- аддитивные технологии;

- сенсоры;
- умные инфраструктуры;

- системы локального позиционирования и навигации.

\section{Инновационные технологии}

в работе с детьми с ограниченными возможностями здоровья

Общегосударственные тенденции развития систем реабилитации и абилитации дифференцированно реализуются в регионах РФ, например в Волгоградской области. Одним из актуальных направлений деятельности специалистов реабилитационного центра «Вдохновение» является разработка и внедрение в деятельность учреждения инновационных социальных технологий.

Государственное бюджетное учреждение социального обслуживания «Волгоградский областной реабилитационный центр “Вдохновение"» создано на основании постановления Администрации Волгоградской области от 26 октября 2017 г. № 562-п «О создании государственного бюджетного учреждения социального обслуживания «Волгоградский областной реабилитационный центр "Вдохновение"» (дата государственной регистрации 12 января 2018 г.).

Основная цель деятельности указанного реабилитационный центра - предоставление социальных услуг в определенное время суток гражданам пожилого возраста и инвалидам, сохранившим или частично утратившим способность к самообслуживанию и нуждающимся в социальном обслуживании, в целях проведения социально-медицинской реабилитации, а также предоставление социальных услуг в определенное время суток детям и подросткам с отклонениями в умственном и физическом развитии в возрасте от рождения до 18 лет с целью осуществления их социальной реабилитации, оказание помощи семьям, имеющим несовершеннолетних с ограниченными возможностями здоровья.

В деятельность специалистов отделения творческой реабилитации была внедрена инновационная социальная технология по развитию детей-инвалидов «Арт-дизайн для детей» [Отделение ... , 2021]. Данная технология составляет основу программы коррекционно-развивающих занятий «Творить, познавая мир», разра- 
ботанной специалистом по комплексной реабилитации настоящего учреждения.

Внедрение инновационной технологии «Арт-дизайн для детей» ориентировано на достижение профессиональной цели - создание условий для коррекции нарушений в развитии детей-инвалидов и детей, попавших в трудную жизненную ситуацию, посредством комплексного совмещения технологий художественного творчества и современных методик декоративно-прикладного творчества [Михайлова и др., 2019]. Характерной особенностью практической реализации технологии «Арт-дизайн для детей» является самостоятельность ребенка в выборе материалов, творческих средств и их цветовой гаммы для изготовления рисунков, аппликаций и поделок, а также возможность их совмещения в зависимости от личных предпочтений ребенка-инвалида. Так, в ходе выполнения одного рисунка или поделки ребенок может совместно использовать краски, цветную бумагу, нитки, пластилин и другие необходимые средства для творческой деятельности.

Целевой группой программы «Творить, познавая мир» являются следующие категории детей:

- дети с задержкой психоречевого развития (ЗПРР);

- дети с синдромом Дауна;

- дети-аутисты;

тия (ЗПР);

- дети с задержкой психического разви-

- дети с детским церебральным параличом (ДЦП);

- дети, нуждающиеся в социальной адаптации (дети, попавшие в трудную жизненную ситуацию).

В ходе реализации программы количество ее участников с подтвержденным диагнозом составило:

- дети с ЗПРР - 2 человека;

- дети с синдромом Дауна - 2 человека;

- дети-аутисты - 9 человек;

- дети с ЗПР - 18 человек;

- дети с ДЦП - 3 человека;

- дети, нуждающиеся в социальной адаптации, -22 человека.

Таким образом, за 2017 г. в реабилитационных занятиях, основанных на применении данной технологии, приняли участие
56 детей, из которых 34 ребенка являются детьми-инвалидами, а 22 ребенка - детьми, попавшими в трудную жизненную ситуацию (см. рис. 2).

В соответствии с содержанием данной коррекционно-развивающей программы основными направлениями работы с детьми-инвалидами являются следующие мероприятия:

1. Диагностическая работа, включающая в себя систематизацию сведений о состоянии развития и личностных интересов ребенка.

2. Коррекционно-развивающие занятия с практическим применением инновационной технологии «Арт-дизайн для детей». Проведение каждого из коррекционно-развивающих занятий ориентировано как на мобилизацию творческого потенциала ребенка и формирование у него творческой жизненной позиции, так и на развитие внутренних механизмов саморегуляции и исцеления. Помимо этого, коррекционные занятия включают в себя элемент планирования ребенком творческого содержания своих занятий.

3. Консультативная работа, включающая в себя индивидуальное консультирование родителей по вопросам взаимодействия с детьми в процессе творчества. Помимо этого, осуществление специалистом консультативноразъяснительной работы благоприятно влияет на повышение уровня открытости в отношениях с ребенком и улучшает качество совместного времяпровождения.

4. Информационно-методическая работа, предполагающая проведение тематических выставок и творческих отчетов по результатам коррекционных занятий. Представление ребенком своих творческих результатов родителям и сверстникам усиливает мотивацию ребенка к проявлению творческих и креативных личностных качеств.

Таким образом, благодаря внедрению инновационной технологии «Арт-дизайн для детей» у детей-инвалидов появилось больше возможностей для самопознания и самовыражения. При этом данная технология имеет потенциал для дальнейшего обновления при помощи различных профессиональных методик, а также устройств и оборудования инновационного характера.

В 2018 г. в деятельность психолого-педагогического отделения Волгоградского об- 


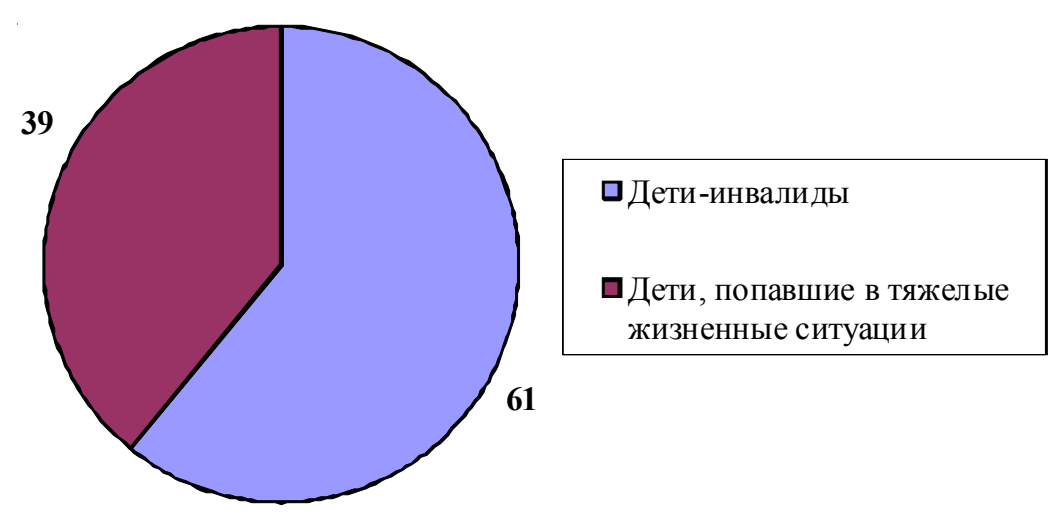

Рис. 2. Категории детей, участвовавших в программе «Творить, познавая мир», \%

Примечание. Составлено авторами по: [Отделение ...].

ластного реабилитационного центра «Вдохновение» была внедрена инновационная форма технологии «Эмбру», традиционный вариант которой предполагает создание рисунков масляными красками на водной поверхности в специальных игрушечных ванночках. Однако с учетом особенностей физиологических и психологических особенностей детей-инвалидов данная технология является технически труднореализуемой. Нестандартным профессиональным решением данной технологической задачи стало изготовление специалистами отделения красочного раствора специального состава и консистенции. Благодаря своим практическим характеристикам данный раствор безопасно помещается в полиэтиленовые пакеты. В свою очередь, тактильное взаимодействие ребенка с раствором, находящимся в плотно запаянном полиэтиленовом пакете, обеспечивает создание неповторимых красочных узоров и вместе с тем значительно повышает уровень положительного психологического настроя ребенка-инвалида. Внедрение инновационной формы технологии «Эмбру» в деятельность настоящего учреждения обеспечило для данной категории детей лучшую проработку мелкой моторики, ориентации в пространстве, а также создало больше условий для восприятия детьми-инвалидами окружающего мира [Suzuki].

В настоящее время специалистами учреждения планируется внедрение инновационных технологий в содержание цикла занятий «Развивающие компьютерные технологии», направленного на помощь детям, не имеющим медицинских противопоказаний, в освоении компьютерных программ обучаю- щего и игрового характера. По мнению специалистов, в занятиях цикла «Развивающие компьютерные технологии» должны присутствовать формы коллективного участия детей-инвалидов в создании различных компьютерных моделей, интерактивных роликов и линейных компьютерных игр.

Таким образом, инновационная технология коррекционно-развивающей направленности «Арт-дизайн для детей» а также инновационная форма психолого-педагогической технологии «Эмбру» составляют инновационный опыт Волгоградского областного реабилитационного центра «Вдохновение». Однако наблюдаемое инновационное развитие отечественной и зарубежной практики социальной работы с детьми-инвалидами обусловливает возможность расширения технологического инструментария специалистов настоящего учреждения.

\section{Заключение}

Теоретические исследования и практика применения человеческого капитала в целях социально-экономического развития территорий показали, что он является одним из мощнейших экономических инструментов.

Основу политики наращивания человеческого капитала должна составить актуализированная и объективно сформированная стратегия социально-экономического развития территории. Основным элементом новой стратегии должны являться мероприятия, направленные на экономический рост, увеличение производительности хозяйствующих субъектов региона, повышение доходности бюдже- 
та, увеличение финансовой обеспеченности социально незащищенных категорий граждан. Дополнительными элементами политики наращивания человеческого капитала региона должно стать развитие образования, здравоохранения и социальной сферы.

В основе целевых показателей развития здравоохранения необходимо предусмотреть создание сети профильных центров оказания высокотехнологичной помощи, развитие детской медицины, повышение уровня обеспеченности лечебно-профилактических учреждений современным оборудованием, медицинскими изделиями и лекарствами, расширение мер поддержки социально незащищенных категорий граждан.

Уровень развития человеческого капитала региона имеет непосредственное влияние на экономическое благосостояние региона, инвестиционную привлекательность территории, социально-культурный облик, структуру миграции, производственную мощность, величину валового регионального продукта и т. д.

Люди, как носители регионального человеческого капитала, в регионах с высоким уровнем данного показателя обладают повышенным уровнем знаний и профессиональных навыков, склонны к постоянному обучению, мобильны, активны, ответственно относятся к своему здоровью, ведут общественную деятельность, что в совокупности само по себе определяет социально-экономическое благополучие территории.

Отдельно необходимо обратить внимание на роль человеческого капитала в построении инновационной экономики, которая в современных условиях стала одним из основных направлений развития. Учитывая, что инновационная экономика представляет собой экономику знаний и информации, человек и человеческий капитал становятся в ней основополагающими ресурсами. Развитие инновационной экономики невозможно без научных разработок, специальных знаний, высококвалифицированного труда, людей, способных быстро и безболезненно адаптироваться к новым условиям.

В заключение следует отметить, что в условиях ограниченности производственных ресурсов и постоянного стремления к экономическому росту роль человеческого капитала постоянно увеличивается. Именно челове- ческий капитал становится основополагающим инструментом в развитии как отдельных регионов, так и государств в целом.

\section{ПРИМЕЧАНИЕ}

${ }^{1}$ Исследование выполнено в рамках технического задания на выполнение научно-исследовательских работ в лаборатории «Исследования в области финансово-экономического обеспечения лиц с инвалидностью» Научно-исследовательского института проблем образования инвалидов ФГБОУИ ВО «Московский государственный гуманитарноэкономический университет».

The research was carried out within the framework of technical assignment on execution of research projects carried out in the "Research in the field of financial and economic support of persons with disability" laboratory of Research Institute for Education for Disabled People, under the "Moscow State University of Humanities and Economics".

\section{СПИСОК ЛИТЕРАТУРЫ}

Байрамов, В. Д. Образование лиц с ограниченными возможностями здоровья в современной России: теоретико-методологические аспекты / В. Д. Байрамов, А. В. Герасимов, А. В. Тюрин. - М. : КНОРУС, 2012. - 127 c.

Инновационно ориентированная региональная политика как базис капитализации и социально-экономический императив развития территории // Вестник Пермского национального исследовательского политехнического университета. Социально-экономические науки. - 2017. - № 3. - С. 192-203. -DOI: https://10. 15593/2224-9354/2017.3.16.

Карпенко, Е. З. Условия формирования и развития человеческого капитала / Е. 3. Карпенко // Региональные проблемы преобразования экономики. -2015 . - № 2. - С. 65-70.

Лаптев, С. В. Человеческий капитал в системе стратегического управления развитием экономики / С. В. Лаптев // Государственное и муниципальное управление. Ученые записки СКАГС. -2016 . - № 2. - С. 87-96.

Михайлова, Н. А. Формирование системы оценки качества и эффективности организационно-управленческой деятельности в сфере социальной работы с детьми-инвалидами / Н. А. Михайлова, Р. Р. Чугумбаев // Финансовая экономика. 2019. -№3.- С. 839-843.

Николаева, А. Н. Роль человеческого капитала в инновационном развитии территории / А. Н. Ни- 
колаева, Е. А. Антипова // Креативная экономика. - 2015. - № 9. - С. 1141-1150. - DOI: https://10.18334/ce.9.9.1927.

Отделение творческой реабилитации ГБУ СО «Волгоградский областной реабилитационный центр “Вдохновение"». - Электрон. текстовые дан. Режим доступа: http://gkuso4303volg.umi.ru/ strany/4. - Загл. с экрана.

Профессиональная ориентация инвалидов в условиях многоуровневого образования: теория и практика. - М. : Экон-Информ, 2017. -451 с.

Bason, C. Powering European Public Sector Innovation: Towards a New Architecture / C. Bason // United Nations Economic Commission for Europe. - New York; Geneva, 2017. - P. 5.

Litvinenko, I. L. Innovation and Digitalization of Economic Processes in Russia / I. L. Litvinenko // Science. Education. Practice : proceedings of the International University Science Forum. Toronto : Infinity Publishing, 2020. - P. 10-21. DOI: https://10.34660/INF.2020.62.12.023.

Suzuki, K. Social Imaging and Human Technology for Empowering People / K. Suzuki. - Electronic text data. - Mode of access: http://ceur-ws.org/Vol2068/symcollab6.pdf. - Title from screen.

\section{REFERENCES}

Bayramov V.D., Gerasimov A.V., Tyurin A.V. Obrazovaniye lits $s$ ogranichennymi vozmozhnostyami zdorov'ya $v$ sovremennoy Rossii: teoretiko-metodologicheskiye aspekty [Education of Persons with Disabilities in Modern Russia: Theoretical and Methodological Aspects]. Moscow, KNORUS Publ., 2012. 127 p.

Balina T.A., Ponomareva Z.V., Stolbov V.A., Tolchin S.V. Innovatsionno oriyentirovannaya regional'naya politika kak bazis kapitalizatsii i sotsial'noekonomicheskiy imperativ razvitiya territorii [Innovation-Oriented Regional Policy As the Basis of Capitalization and Socio-Economic Imperative of the Development of the Area]. Vestnik Permskogo natsional'nogo issledovatel'skogo politekhnicheskogo universiteta. Sotsial'no-ekonomicheskiye nauki [PNRPU Sociology and Economics Bulletin], 2017, no. 3, pp. 192-203. DOI: https:// 10.15593/2224-9354/2017.3.16.

Karpenko E.Z. Usloviya formirovaniya i razvitiya chelovecheskogo kapitala [Conditions of
Formation and Development of Human Capital]. Regional'nyye problemy preobrazovaniya ekonomiki, 2015, no. 2, pp. 65-70.

Laptev S.V. Chelovecheskiy kapital v sisteme strategicheskogo upravleniya razvitiyem ekonomiki [Human Capital in the System of Strategic Management of Economy Development]. Gosudarstvennoye $i$ munitsipal'noye upravleniye. Uchenyye zapiski SKAGS [State and Municipal Management. Scientific Notes of SKAGS], 2016, no. 2, pp. 87-96.

Mikhaylova N.A., Chugumbaev R.R. Formirovaniye sistemy otsenki kachestva i effektivnosti organizatsionno-upravlencheskoy deyatel'nosti v sfere sotsial'noy raboty s det'mi-invalidami [Formation of the System for Assessing the Quality and Efficiency of Organizational and Management Activities in the Sphere of Social Work with Disabled Children]. Finansovaya ekonomika, 2019, no. 3, pp. 839-843.

Nikolaeva A.N., Antipova E.A. Rol' chelovecheskogo kapitala $v$ innovatsionnom razvitii territorii [The Role of Human Capital in the Innovative Development of a Territory]. Kreativnaya ekonomika, 2015, no. 9, pp. 1141-1150. DOI: https://10.18334/ce.9.9.1927.

Otdeleniye tvorcheskoy reabilitatsii GBU SO "Volgogradskiy oblastnoy reabilitatsionnyy tsentr "Vdokhnovenie"”[Department of Creative Rehabilitation GBU SO "Volgograd Regional Rehabilitation Center 'Vdokhnovenie"']. URL: http://gkuso4303volg.umi.ru/strany/4.

Gerasimov A.V. et al. Professionalnaya orientatsiya invalidov $v$ usloviyakh mnogourovnevogo obrazovaniya: teoriya i praktika [Professional Orientation of Persons with Disabilities in MultiLevel Education: Theory and Practice]. Moscow, Ekon-Inform Publ., 2017. 451 p.

Bason C. Powering European Public Sector Innovation: Towards a New Architecture. United Nations Economic Commission for Europe. New York, Geneva, 2017, p. 5.

Litvinenko I.L. Innovation and Digitalization of Economic Processes in Russia. Science. Education. Practice. Proceedings of the International University Science Forum. Toronto, Infinity Publishing, 2020, pp. 10-21. DOI: https://10.34660/INF.2020.62.12.023.

Suzuki K. Social Imaging and Human Technology for Empowering People. URL: http://ceur-ws.org/ Vol-2068/symcollab6.pdf. 
Н.А. Михайлова, И.Л. Литвиненко. Инновационные технологии развития человеческого капитала детей с ОВ3

\section{Information About the Authors}

Nataliya A. Mikhaylova, Candidate of Sciences (Economics), Associate Professor, Department of Economy and Innovation, Moscow State University of Humanities and Economics, Losinoostrovskaya St, 49, 107150 Moscow, Russian Federation, korish.m@volsu.ru, https://orcid.org/0000-0002-3747-3587

Inna L. Litvinenko, Candidate of Sciences (Economics), Associate Professor, Department of Management and Entrepreneurship, Moscow State University of Humanities and Economics, Losinoostrovskaya St, 49, 107150 Moscow, Russian Federation, innalitvinenko@yandex.ru, https://orcid.org/0000-0002-6102-5012

\section{Информация об авторах}

Наталия Александровна Михайлова, кандидат экономических наук, доцент, доцент кафедры экономики и инноваций, Московский государственный гуманитарно-экономический университет, ул. Лосиноостровская, 49, 107150 г. Москва, Российская Федерация, korish.m@volsu.ru, https://orcid.org/0000-0002-3747-3587

Инна Леонтьевна Литвиненко, кандидат экономический наук, доцент кафедры управления и предпринимательства, Московский государственный гуманитарно-экономический университет, ул. Лосиноостровская, 49, 107150 г. Москва, Российская Федерация, innalitvinenko@yandex.ru, https://orcid.org/0000-0002-6102-5012 